\title{
Contribution of new water vapor absorption lines to the atmospheric transmission in the transparency window 8-12 $\mu \mathrm{m}$
}

Voronina, Yu., Chesnokova, T. Yu., Voronin, B., Yurchenko, S.

Yu. V. Voronina, T. Yu. Chesnokova, B. A. Voronin, S. N. Yurchenko, "Contribution of new water vapor absorption lines to the atmospheric transmission in the transparency window 8-12 $\mu \mathrm{m}$," Proc. SPIE 11560, 26th International Symposium on Atmospheric and Ocean Optics, Atmospheric Physics, 115600B (12 November 2020); doi: 10.1117/12.2575547

Event: 26th International Symposium on Atmospheric and Ocean Optics, Atmospheric Physics, 2020, Moscow, Russian Federation 


\title{
Contribution of new water vapor absorption lines to the atmospheric transmission in the transparency window 8-12 $\mu \mathrm{m}$
}

\author{
Voronina Yu.V. ${ }^{1}$, Chesnokova T.Yu. ${ }^{1}$, Voronin B.A. ${ }^{1}$, Yurchenko S.N. ${ }^{2}$ \\ ${ }^{1}$ V.E. Zuev Institute of Atmospheric Optics SB RAS, 1, Academician Zuev square, 634055, Tomsk, \\ Russia \\ ${ }^{2}$ Department of Physics and Astronomy, University College London, Gower St., London WC1E \\ 6BT, UK \\ e-mail: yulia@iao.ru, ches@iao.ru, vba@iao.ru, s.yurchenko@ucl.ac.uk
}

\begin{abstract}
The evaluation of the contribution of numerous $\mathrm{H}_{2} \mathrm{O}$ absorption lines to the atmospheric transmission in the 8-12 $\mu \mathrm{m}$ transparency window is presented based on different spectroscopic databases of water vapor absorption lines, including the new theoretical data sets POKAZATEL and VoTe, as well as the $\mathrm{H}_{2} \mathrm{O}$ data from the popular spectroscopic databases HITRAN and GEISA. Comparison of the atmospheric transmittance calculated using different databases is presented. The contribution of the weak lines is investigated and shown to be important for very long absorption paths.
\end{abstract}

Keywords: water vapor, atmospheric transmission, absorption line parameters

\section{INTRODUCTION}

Water vapor continuum plays main role in the atmospheric transparency window between 8 and $12 \mu \mathrm{m}$, with significant influence on radiative fluxes ${ }^{1,2}$. The $\mathrm{H}_{2} \mathrm{O}$ continuum is determined as difference between measured absorption of $\mathrm{H}_{2} \mathrm{O}$ and absorption calculated using line parameters from spectroscopic databases. Therefore, precise and full knowledge of $\mathrm{H}_{2} \mathrm{O}$ absorption line parameters is important.

Recently, new theoretical $\mathrm{H}_{2} \mathrm{O}$ line parameters data set POKAZATEL ${ }^{3}$ (www.exomol.com) was published. The distinctive feature of the new line list is its completeness. POKAZATEL contains all transitions of $\mathrm{H}_{2} \mathrm{O}$ within the ground electronic state between all energy levels up to dissociation $\left(\sim 40000 \mathrm{~cm}^{-1}\right)$ with no intensity, energy or quantum numbers cut-offs. The rotational angular momentum quantum number changes in the range from $J=0$ to $J_{\max }=69$. POKAZATEL contains 810269 states and about 5 billion transitions. The previous extensive water line list BT2 ${ }^{4}$ contains only 500 million transitions in the range up to $30000 \mathrm{~cm}^{-1}$ with the number of states about 220000 . Presently, POKAZATEL is the most complete calculated line list for the $\mathrm{H}_{2} \mathrm{O}$ molecule and can be applied in the simulation of absorption and emission spectra overa wide range of temperatures and spectral regions. POKAZATEL is based on the refinement of an $a b$ initio potential energy surface by fitting to limited experimental data. The weak point of any empirical line lists is that the accuracy drops outside the spectroscopic region directly used in the empirical refinement. To mitigate this problem, some of the empirically determined line positions in POKAZATEL ${ }^{3}$ were replaced by the experimental values ${ }^{5}$, where available.

Empirical line lists are found useful in some spectral applications, for example, study of Mars ${ }^{6}$. It is known that the intensity cut-offs have impact in different spectroscopic regions and is especially important at for long wavelengths. For example, HITRAN uses a dynamic intensity cut-off, exponentially increasing for very small values of the frequency. This is illustrated in Fig. 1, which shows intensities of $\mathrm{H}_{2} \mathrm{O}$ absorption lines from the POKAZATEL line list in the 800$1250 \mathrm{~cm}^{-1}$ transparency window for different values of the intensity cut-offs. 


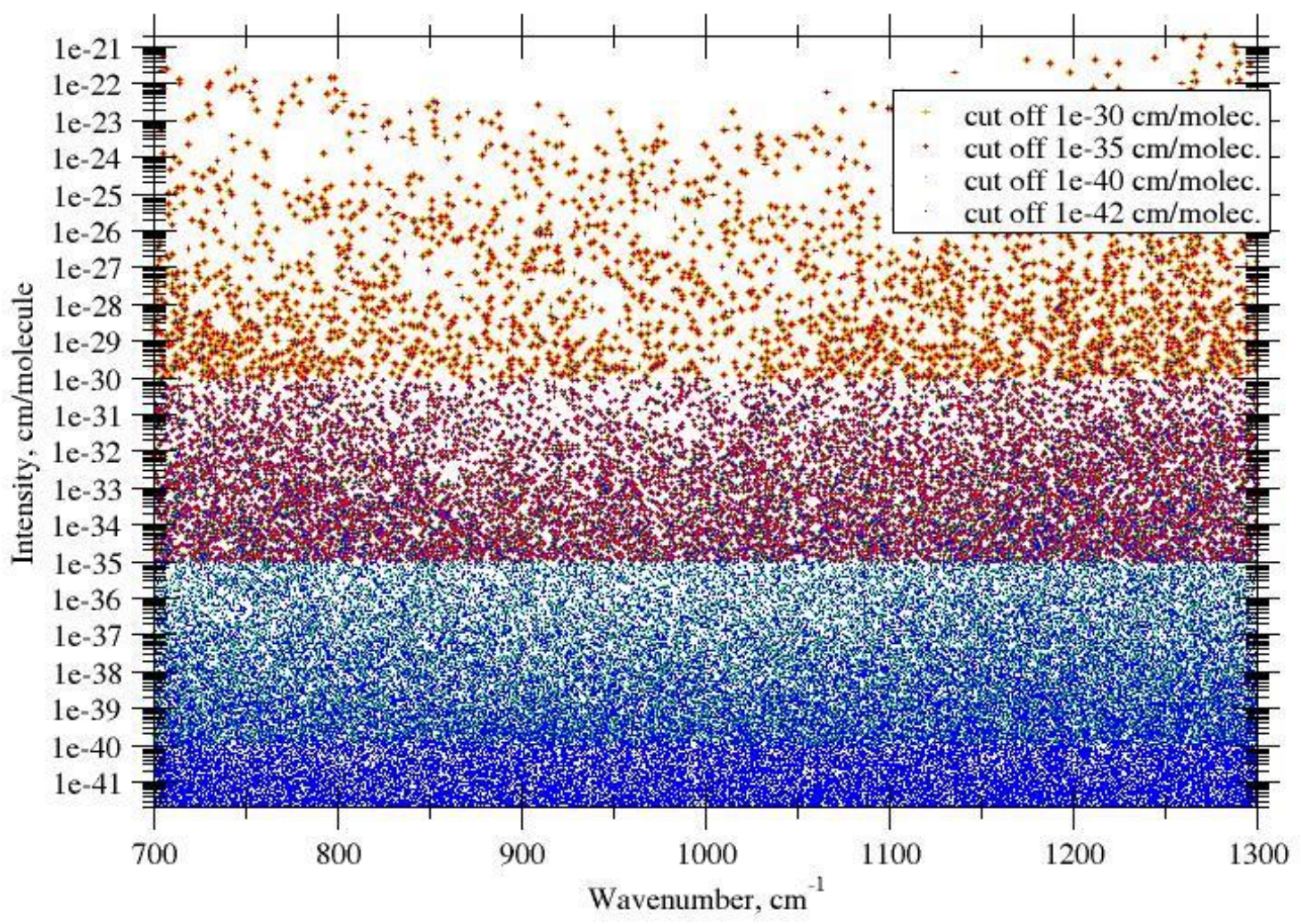

Fig. 1. Intensities of $\mathrm{H}_{2}{ }^{16} \mathrm{O}$ absorption lines in POKAZATEL for different values of intensity cut-offs.

It should be noted that in this study we took advantage of the assignment of the water transitions with $J_{\max }=40$ provided by S. Tashkun ${ }^{7}$ with the help of earlier Partridge and Schwenke' calculations and a wave functions analysis.

Recently an $\mathrm{H}_{2} \mathrm{O}$ line list $\mathrm{VoTe}^{8}$ with $J_{\max }=50$ was produced using the same potential energy surface as for POKAZATEL ${ }^{9}$ but including energy levels only up to $25000 \mathrm{~cm}^{-1}$, where possible, with more accurate wavenumbers.

The aim of this work is to estimate a contribution of numerous weak absorption lines of $\mathrm{H}_{2} \mathrm{O}$, predicted by POKAZATEL and VoTe, to the absorption of thermal radiation for long paths in the atmospheric transparency window 8-12 $\mu \mathrm{m}$, and to estimate the atmospheric path lengths where this contribution becomes noticeable. Also, it was interesting to compare the results of VoTe and POKAZATEL with the calculations of the atmospheric transmission using the spectroscopic databases HITRAN and GEISA, which are popular in atmospheric applications.

\section{CALCULATION OF ATMOSPHERIC TRANSMISSION WITH DIFFERENT $\mathrm{H}_{2} \mathrm{O}$ LINE PARAMETERS DATABASES}

The line-by-line calculations of atmospheric transmission requires a set of parameters defining the line shape. The pressure broadening parameters (air- and self-broadening coefficients or temperature-dependence exponent) provided in POKAZATEL have a very limited quantum number dependence ( $\mathrm{J}$ "-only). Moreover, a complete rotationalvibrational assignment is provided only for $\sim 13000$ energy levels out of 800000 reference data ${ }^{5}$. For all other states, POKAZATEL provides $J$ and the symmetry number only. Therefore, in our atmospheric simulations an extended set of line broadening parameters ( $J^{\prime \prime}$, and $J^{\prime} J^{\prime \prime}$-dependences) from work ${ }^{10}$ was used. The atmospheric transmission was calculated line-by-line ${ }^{11}$ with the spectral resolution of $0.001 \mathrm{~cm}^{-1}$ at a variation of the atmospheric path lengths towards 
an integral transmission in the 8-12 $\mu$ mindow. The $\mathrm{H}_{2}{ }^{16} \mathrm{O}$ absorption lines from POKAZATEL ${ }^{3}$, VoTe ${ }^{9}$, UCL08 ${ }^{12}$ as well as from different versions of HITRAN ${ }^{13-15}$ and GEISA ${ }^{16,17}$ were used in the simulations. The line parameters of other water isotopologues and atmospheric gases were taken from HITRAN2016. The $\mathrm{H}_{2} \mathrm{O}$ continuum absorption was taken into account according to the MT_CKD2.5 model ${ }^{18}$.

We used the mid latitude summer AFGL model ${ }^{19}$ for the vertical profiles of pressure, temperature and concentration of atmospheric gases. The atmosphere was divided into 46 layers from 0 to $100 \mathrm{~km}$ with constant values of pressure, temperatures and gases concentrations. The transmissions were calculated at slant path through the atmosphere at zenith angle of $75^{\circ}$. The atmospheric transmission and difference between transmissions calculated using $\mathrm{H}_{2}{ }^{16} \mathrm{O}$ line parameters from different spectroscopic databases are presented in Fig. 2. There is a good agreement between the transmissions simulated with latest spectroscopic databases HITRAN2016 and GEISA2015, with the difference not exceeding 0.01.
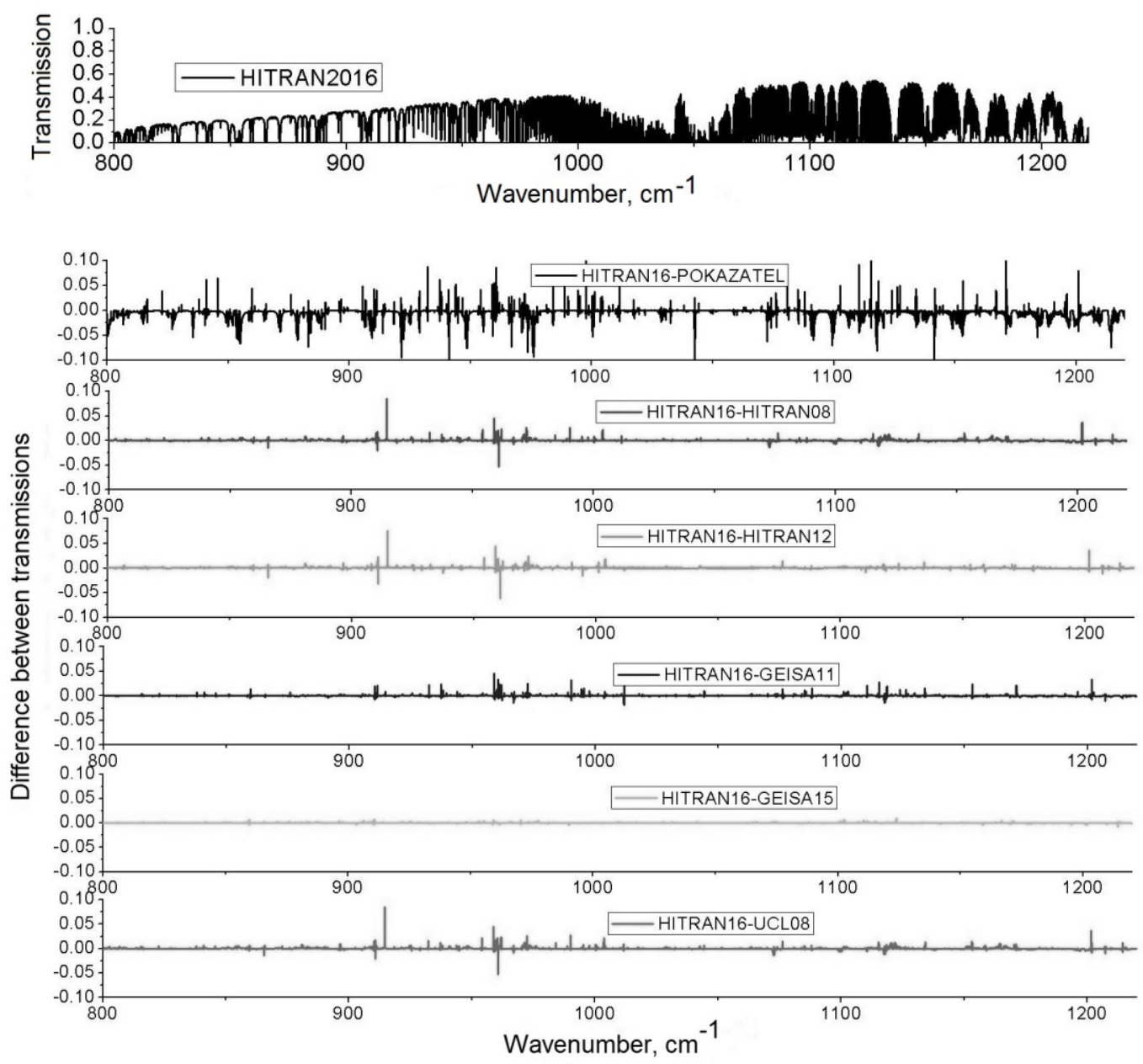

Fig. 2 The atmospheric transmission and difference between transmissions calculated with $\mathrm{H}_{2} \mathrm{O}$ line parameters from different spectroscopic databases

The comparison of the integral transmission in the $820-1200 \mathrm{~cm}^{-1}$ spectral region, calculated with $\mathrm{H}_{2} \mathrm{O}$ line parameters from different spectroscopic databases at vertical and slant paths for the atmospheric models of mid latitude summer and tropics is presented in Tables 1 and 2 (referenced to as POKAZATEL $10^{-42}$ and VoTe $10^{-42}$, respectively). The intensity cut-off value was set to $10^{-42} \mathrm{~cm} /$ molecule for POKAZATEL and VoTe. As it is shown in Table 2, the relative difference between the integral transmission calculated with HITRAN2016 and POKAZATEL reaches $2.5 \%$ for the mid latitude summer model. The difference between the results obtained using HITRAN2016 and other versions of HITRAN and GEISA does not exceed $0.2 \%$. 
The same comparison of the atmospheric transmissions was made for a horizontal path of various lengths and illustrated in Table 3-8. The relative difference between the transmissions, calculated using $\mathrm{H}_{2} \mathrm{O}$ line parameters from different spectroscopic databases increases by several times at the path length increasing. For example, comparison of the transmissions calculated using last versions of HITRAN2016 and GEISA2015 has shown an increase in the relative difference by an order $(0.04 \%$ at $1 \mathrm{~km}$ length and $0.4 \%$ at $100 \mathrm{~km})$.

To estimate the contribution of numerous weak $\mathrm{H}_{2} \mathrm{O}$ lines in POKAZATEL and VoTe, we have calculated the atmospheric transmission using two intensity cutoffs, $10^{-42}$ and $10^{-40} \mathrm{~cm} /$ molecule. The contribution from the VoTe $\mathrm{H}_{2} \mathrm{O}$ weak lines to the atmospheric transmission via a horizontal path of $10 \mathrm{~km}$ length can reach up to $0.46 \%$ (see Table 4). This contribution is less for the POKAZATEL lines, and it is only $0.002 \%$ for the atmospheric path of $100 \mathrm{~km}$.

Table 1 The integral transmission in the $820-1200 \mathrm{~cm}^{-1}$ spectral region, calculated with $\mathrm{H}_{2} \mathrm{O}$ line parameters from different spectroscopic databases at vertical and slant paths for the atmospheric models of mid latitude summer (MLS) and tropics (TRP).

\begin{tabular}{|l|l|l|l|l|l|l|l|l|}
\hline $\begin{array}{l}\text { Atmospheric } \\
\text { model }\end{array}$ & $\begin{array}{l}\text { HITRAN } \\
2016\end{array}$ & $\begin{array}{l}\text { POKAZ } \\
\text { ATEL } \\
10^{-42}\end{array}$ & $\begin{array}{l}\text { VoTe } \\
10^{-42}\end{array}$ & $\begin{array}{l}\text { HITRAN } \\
2012\end{array}$ & $\begin{array}{l}\text { HITRAN } \\
2008\end{array}$ & $\begin{array}{l}\text { GEISA } \\
2011\end{array}$ & $\begin{array}{l}\text { GEISA } \\
2015\end{array}$ & UCL08 \\
\hline MLS, SZA $=0^{0}$ & 0.6116 & 0.6178 & 0.6161 & 0.6110 & 0.6110 & 0.6113 & 0.6112 & 0.6110 \\
\hline MLS, SZA $=75^{0}$ & 0.2338 & 0.2397 & 0.2382 & 0.2333 & 0.2334 & 0.2336 & 0.2335 & 0.2334 \\
\hline TRP, SZA $=75^{0}$ & 0.1338 & 0.1378 & 0.1368 & 0.1335 & 0.1336 & 0.1338 & 0.1337 & 0.1336 \\
\hline
\end{tabular}

Table 2 Relative difference $(\%)$ in the integral transmission in the $820-1200 \mathrm{~cm}^{-1}$ spectral region, calculated with $\mathrm{H}_{2} \mathrm{O}$ line parameters from the HITRAN2016 and from other spectroscopic databases.

\begin{tabular}{|l|l|l|c|c|c|c|c|}
\hline $\begin{array}{l}\text { Atmospheric } \\
\text { model }\end{array}$ & $\begin{array}{l}\text { POKAZ } \\
\text { ATEL } \\
10^{-42}\end{array}$ & $\begin{array}{l}\text { VoTe } \\
10^{-42}\end{array}$ & $\begin{array}{l}\text { HITRAN } \\
2012\end{array}$ & $\begin{array}{l}\text { HITRAN } \\
2008\end{array}$ & $\begin{array}{l}\text { GEISA } \\
2011\end{array}$ & $\begin{array}{l}\text { GEISA } \\
2015\end{array}$ & UCL08 \\
\hline MLS, SZA $=0^{0}$ & 1.0 & 0.7 & 0.1 & 0.1 & 0.05 & 0.06 & 0.1 \\
\hline MLS, SZA $=75^{0}$ & 2.5 & 1.8 & 0.2 & 0.2 & 0.08 & 0.13 & 0.2 \\
\hline TRP, SZA $=75^{0}$ & 2.9 & 2.2 & 0.2 & 0.1 & 0 & 0.07 & 0.1 \\
\hline
\end{tabular}

Table 3. The atmospheric transmission via a horizontal path, calculated using $\mathrm{H}_{2} \mathrm{O}$ line parameters from different spectroscopic databases

\begin{tabular}{|l|l|l|l|l|l|l|}
\hline L, $\mathrm{km}$ & HITRAN2016 & HITRAN2012 & HITRAN2008 & GEISA2011 & GEISA2015 & UCL08 \\
\hline 1 & 0.7012 & 0.7007 & 0.7005 & 0.7007 & 0.7009 & 0.7005 \\
\hline 10 & 0.1066 & 0.1063 & 0.1064 & 0.1065 & 0.1064 & 0.1064 \\
\hline 100 & $3.7586 \mathrm{E}-7$ & $3.7333 \mathrm{E}-7$ & $3.7445 \mathrm{E}-7$ & $3.7723 \mathrm{E}-7$ & $3.7418 \mathrm{E}-7$ & $3.7325 \mathrm{E}-7$ \\
\hline
\end{tabular}

The difference between the HITRAN2016, POKAZATEL, and VoTe results in Tables 1 and 2 can be explained by the differences in the broadening coefficients used in the simulations. In order to better understand this discrepancies the following schemes of the self- and air-broadened half-widths $\left(\gamma_{\text {self }}\right.$ and $\left.\gamma_{\text {air }}\right)$, and temperature dependence exponent $\left(\mathrm{n}_{\mathrm{t}}\right)$ were tested:

1. HWJJ: $\gamma_{\text {self }}, \gamma_{\text {air }}$ and $\mathrm{n}_{\mathrm{t}}$ are calculated using the J'-, J'J"'-dependences ${ }^{10}$;

2. HWconst: $\gamma_{\text {air }}=0.075 ; \gamma_{\text {self }}=0.67$ and $n_{t}=0.4$ as in POKAZATEL $^{3}$;

3. HWGtKtd: $\gamma_{\text {air }}=0.075 ; \gamma_{\text {self }}$ and $n_{t}$ are calculated using the J'-, J'J"-dependences ${ }^{10}$;

4. HWPtashnik: $\gamma_{\text {air }}$ is according to the approximation of Ptashnik et $\mathrm{al}^{20} ; \gamma_{\mathrm{self}}=0.67$ and $\mathrm{n}_{\mathrm{t}}=0.4$;

5. HW: $\gamma_{\text {air }}=\max \left(-0.0046875 \mathrm{~J}^{\prime \prime}+0.1,0.024\right) ; \quad \mathrm{n}_{\mathrm{t}}=\max (-0.0225 \mathrm{~J} "+0.76,0.31)$;

$\gamma_{\text {self }}=\max (-0.015625 \mathrm{~J} "+0.49,0.24)$. 
The atmospheric transmission via a horizontal path, calculated using the schemes of the self- and air-broadened half-widths above is presented in Table 4 for VoTe, and in Table 5 for POKAZATEL. Relative differences between transmissions obtained using these schemes and that using HITRAN2016 is presented in Table 7 and 8 for VoTe and POKAZATEL, correspondingly. The closest results to HITRAN2016 were observed for the VoTe simulation using the HWPtashnik approximation of $\gamma_{\text {air, }}$, where difference in the transmissions was $0.04 \%$ for a horizontal path of $1 \mathrm{~km}$. The difference from HITRAN2016 for other schemes of broadening coefficients was $0.4 \%$ and higher. For comparison, the transmission calculated with HITRAN2008, HITRAN2012, GEISA2011, GEISA2015, UCL08 differ from the HITRAN2016 results by no more than $0.1 \%$ (Table 6 ).

Table 4. The atmospheric transmission through a horizontal path, calculated with the $\mathrm{H}_{2} \mathrm{O}$ line list VoTe using different approximations of the self- and air-broadened half-widths

\begin{tabular}{|l|l|l|l|l|l|}
\hline $\mathrm{L}, \mathrm{km}$ & $\begin{array}{l}\text { VoTe } \\
10^{-42}\end{array}$ & $\begin{array}{l}\text { VoTe } \\
\text { HWJJ }\end{array}$ & $\begin{array}{l}\text { VoTe } \\
\text { HWJ }\end{array}$ & $\begin{array}{l}10^{-42} \\
\text { Hwconst }\end{array}$ & $\begin{array}{l}\text { VoTe } \\
10^{-42}\end{array}$ \\
HWGtKtd & $\begin{array}{l}\text { VoTe } \\
\text { HWPtashnik }\end{array}$ \\
\hline 1 & 0.7053 & 0.7053 & 0.6961 & 0.6986 & 0.7009 \\
\hline 10 & 0.1093 & 0.1098 & 0.1033 & 0.1048 & 0.1065 \\
\hline 100 & $4.2426 \mathrm{E}-7$ & $4.2423 \mathrm{E}-7$ & $3.3237 \mathrm{E}-7$ & $3.5651 \mathrm{E}-7$ & $3.8280 \mathrm{E}-7$ \\
\hline
\end{tabular}

Table 5. The atmospheric transmission through a horizontal path, calculated with the $\mathrm{H}_{2} \mathrm{O}$ line list POKAZATEL using different approximations of the self- and air-broadened half-widths

\begin{tabular}{|l|l|l|l|l|}
\hline L, km & $\begin{array}{l}\text { Pokazatel } \\
10^{-42} \\
\text { HWJJ }\end{array}$ & $\begin{array}{l}\text { Pokazatel } \\
10^{-30} \\
\text { HWJJ }\end{array}$ & $\begin{array}{l}\text { Pokazatel } \\
10^{-42} \\
\text { HWconst }\end{array}$ & $\begin{array}{l}\text { Pokazatel } \\
10^{-42} \\
\text { HW }\end{array}$ \\
\hline 1 & 0.7055 & 0.7055 & 0.6963 & 0.7064 \\
\hline 10 & 0.1095 & 0.1095 & 0.1034 & 0.1098 \\
\hline 100 & $4.2522 \mathrm{E}-7$ & $4.2523 \mathrm{E}-7$ & $3.3333 \mathrm{E}-7$ & $4.4041 \mathrm{E}-7$ \\
\hline
\end{tabular}

Table 6 Relative difference $(\%)$ in the atmospheric transmission, calculated with $\mathrm{H}_{2} \mathrm{O}$ line parameters from the HITRAN2016 and from other spectroscopic databases.

\begin{tabular}{|l|l|l|l|l|l|}
\hline $\mathrm{L}, \mathrm{km}$ & HITRAN2012 & HITRAN2008 & GEISA2011 & GEISA2015 & UCL08 \\
\hline 1 & 0.07 & 0.1 & 0.07 & 0.04 & 0.1 \\
\hline 10 & 0.3 & 0.2 & 0.1 & 0.2 & 0.2 \\
\hline 100 & 0.7 & 0.4 & 0.4 & 0.4 & 0.7 \\
\hline
\end{tabular}

Table 7 Relative difference (\%) between atmospheric transmissions, calculated with the HITRAN2016 database and the line list VoTe using different approximations of the self- and air-broadened half-widths

\begin{tabular}{|l|l|l|l|l|l|}
\hline L, km & $\begin{array}{l}\text { VoTe } \\
10^{-42} \\
\text { HWJJ }\end{array}$ & $\begin{array}{l}\text { VoTe } \\
10^{-30} \\
\text { HWJ }\end{array}$ & $\begin{array}{l}\text { VoTe } \\
10^{-42}\end{array}$ & $\begin{array}{l}\text { VoTe } \\
10^{-42} \\
\text { Hwconst }\end{array}$ & $\begin{array}{l}\text { VoTe } \\
10^{-42} \\
\text { HWPtashnik }\end{array}$ \\
\hline 1 & 0.6 & 0.6 & 0.7 & 0.4 & 0.04 \\
\hline 10 & 2.5 & 2.5 & 3.1 & 1.7 & 0.09 \\
\hline 100 & 11.41 & 11.40 & 11.57 & 5.15 & 1.81 \\
\hline
\end{tabular}


Table 8 Relative difference $(\%)$ between the atmospheric transmissions, calculated with POKAZATEL and HITRAN2016.

\begin{tabular}{|l|l|l|l|l|}
\hline L, km & $\begin{array}{l}\text { Pokazatel } \\
10^{-42} \\
\text { HWJJ }\end{array}$ & $\begin{array}{l}\text { Pokazatel } \\
10^{-30} \\
\text { HWJJ }\end{array}$ & $\begin{array}{l}\text { Pokazatel } \\
10^{-42} \\
\text { HWconst }\end{array}$ & $\begin{array}{l}\text { Pokazatel } \\
10^{-42} \\
\text { HW }\end{array}$ \\
\hline 1 & 0.6 & 0.6 & 0.7 & 0.7 \\
\hline 10 & 2.65 & 2.65 & 3.0 & 2.9 \\
\hline 100 & 11.608 & 11.610 & 11.315 & 14.66 \\
\hline
\end{tabular}

\section{CONCLUSION}

A comparison of the atmospheric transmissions in the $820-1200 \mathrm{~cm}^{-1}$ spectral region calculated using different $\mathrm{H}_{2} \mathrm{O}$ line lists is carried out. The relative difference between the results obtained using HITRAN2016 and other versions of HITRAN and GEISA does not exceed $0.2 \%$ at slant path with zenith angle of $75^{\circ}$ for mid latitude summer. The difference between the integral transmissions calculated using HITRAN2016 and POKAZATEL is about $2.5 \%$ which can be partly explained by different approaches using for broadening coefficients.

The atmospheric transmission using different approximations of the self- and air-broadened half-widths and temperature dependence exponents was simulated. It was shown that the closest results to the HITRAN2016 were observed for the VoTe simulation using the HWPtashnik approximation of the air-broadened half-width [20] where the difference in the transmissions was $0.04 \%$ for a horizontal path of $1 \mathrm{~km}$. The difference from the HITRAN2016 for other approximations of broadening coefficients was $0.4 \%$ and more. According to VoTe, the difference with HITRAN becomes significant for path lengths of $100 \mathrm{~km}$, where using more complete datasets is important.

The contribution of VoTe $\mathrm{H}_{2} \mathrm{O}$ weak lines (less than $10^{-30} \mathrm{~cm} / \mathrm{molecule}$ ) to the atmospheric transmission via a horizontal path of the $10 \mathrm{~km}$ can reach up to $0.46 \%$.

\section{Acknowledgments}

This work was financially supported under the project of the Program of Fundamental Scientific Research of State Academies of Sciences, as well as with partial support of grants RFBR №19-03-00389 and RFBR №18-45-700011 r_a.

\section{References}

[1] Paynter, D. J., Ramaswamy, V., “An assessment of recent water vapor continuum measurements upon longwave and shortwave radiative transfer", J. Geophys. Res., 116, D20302 (2011)

[2] Clough, S. A., Iacono, M. J., Moncet, J. L., "Line-by-line calculations of atmospheric fluxes and cooling rates: Application to water vapor," J. Geophys. Res., 97, 15761-15785 (1992)

[3] Polyansky, O. L, Kyuberis, A. A., Zobov, N. F., Tennyson, J., Yurchenko, S. N., Lodi, L., "ExoMol molecular line lists XXX: a complete high-accuracy line list for water," Monthly Notices of the Royal Astronomical Society., 480(2), 2597-2608 (2018)

[4] Barber, R.J., Tennyson, J., Harris, G.J., Tolchenov, R.N. "A high accuracy computed water line list - BT2," Mon. Not. R. Astron. Soc., 368, 1087 (2006)

[5] Tennyson, J., Bernath, P.F., Brown L.R., Campargue, A., Császár, A. G., Daumont, L., Gamache, R. R., Hodges, J. T., Naumenko, O. V., Polyansky, O. L., Rothman, L. S., Vandaele, A. C., Zobov, N. F., Al Derzi, A. R., Fábri, C., Fazliev, A. Z., Furtenbacher, T., Gordon, I. E., Lodi, L., Mizus, I. I. "IUPAC critical evaluation of the rotational-vibrational spectra of water vapor, Part III: Energy levels and transition wavenumbers for $\mathrm{H}_{2}{ }^{16} \mathrm{O}$," JQSRT, 117, 29-58 (2013)

[6] Lavrentieva, N.N., Voronin, B.A., Naumenko, O.V., Bykov, A.D., Fedorova, A.A. "Linelist of HD ${ }^{16}$ O for study of atmosphere of terrestrial planets (Earth, Venus and Mars)," Icarus, 236, 38-47 (2014).

[7] http://spectra.iao.ru/molecules

[8] Voronin, B.A., Tennyson, J., Lodi, L., Kozodoev, A.V. "The VoTe Room Temperature $\mathrm{H}_{2}{ }^{16} \mathrm{O}$ Line List up to $25000 \mathrm{~cm}^{-1}$," Optics and Spectroscopy, 127(6), 967-973 (2019) 
[9] Mizus, I. I., Kyuberis, A A., Zobov, N. F., Makhnev, V. Yu., Polyansky, O.L., and Tennyson, J., "High accuracy water potential energy surface for the calculation of infrared spectra," Philos. Trans. Royal Soc. London A 376, 20170149 (2018).

[10] Voronin, B.A., Lavrentieva, N. N., Mishina, T. P., Chesnokova, T.Yu., Barber, M. J., Tennyson, J. "Estimate of the J'J dependence of water vapor line broadening parameters," J. Quant. Spectrosc. Radiat. Transfer, 111, 2308-2314 (2010)

[11] Mitsel, A.A., Ptashnik, I.V., Firsov, K.M., Fomin, B.A. "Efficient technique for line-by-line calculating the transmittance of the absorbing atmosphere," Atmospheric and Oceanic Optics, 8(10), 847-850 (1995)

[12] Shillings, A. J. L., Ball, S. M., Barber, M. J., Tennyson, J., and Jones, R. L. "An Upper Limit for Water Dimer Absorption in the $750 \mathrm{~nm}$ Spectral Region and a Revised Water Line List," Atmospheric Chemistry and Physics, 11(9), 4273-4287 (2011)

[13] Rothman, L.S., Gordon, I.E., Barbe, A., Benner, D.C., Bernath, P.F., Birk, M., Boudon, V., Brown, L.R., Campargue, A., Champion, J.-P., Chance, K., Coudert, L.H., Dana, V., Devi, V.M., Fally, S., Flaud, J.-M., Gamache, R.R., Goldman, A., Jacquemart, D., Kleiner, I., Lacome, N., Lafferty, W.J., Mandin, J.-Y., Massie, S.T., Mikhailenko, S.N., Miller, C.E., Moazzen-Ahmadi, N., Naumenko, O., Nikitin, A.V., Orphal, J., Perevalov, V.I., Perrin, A., Predoi-Cross, A., Rinsland, C.P., Rotger, M., Simecková, M., Smith, M.A.H., Sung, K., Tashkun, S.A., Tennyson, J., Toth, R.A., Vandaele, A.C., Vander Auwera, J., "The HITRAN 2008 molecular spectroscopic database," J. Quant. Spectrosc. Radiat. Transfer, 110 (9-10), 533-572 (2009)

[14] Rothman, L.S., Gordon, I.E., Babikov, Y., Barbe, A., Benner, D.C., Bernath, P.F., Birk, M., Bizzocchi, L., Boudon, V., Brown, L.R., Campargue, A., Chance, K., Cohen, E.A., Coudert, L.H., Devi, V.M., Drouin, B.J., Fayt, A., Flaud, J.-M., Gamache, R.R., Harrison, J.J., Hartmann, J.-M., Hill, C., Hodges, J.T., Jacquemart, D., Jolly, A., Lamouroux, J., Le Roy, R.J., Li, G., Long, D.A., Lyulin, O.M., Mackie, C.J., Massie, S.T., Mikhailenko, S., Müller, H.S.P., Naumenko, O.V., Nikitin, A.V., Orphal, J., Perevalov, V., Perrink, A., Polovtseva, E.R., Richard, C., Smith, M.A.H., Starikova, E., Sung, K., Tashkun, S., Tennyson, J., Toon, G.C., Tyuterev, Vl.G., Wagner, G, "The HITRAN2012 molecular spectroscopic database," J. Quant. Spectrosc. Radiat. Transfer, 130, 4-50 (2013)

[15] Gordon,, I.E., Rothman, L.S., Hill, C., Kochanov, R.V., Tan, Y., Bernath, P.F., Birk, M., Boudon, V., Campargue, A., Chance, K.V., Drouin, B.J., Flaud, J.-M., Gamache, R.R., Hodges, J.T., Jacquemart, D., Perevalov V.I., Perrin A., Shine K.P., Smith M.-A.H., Tennyson J., Toon G.C., Tran H., Tyuterev V.G., Barbe A., Császár, A.G., Devi, V.M., Furtenbacher, T., Harrison, J.J., Hartmann, J.-M., Jolly, A., Johnson, T.J., Karman, T., Kleiner, I., Kyuberis, A.A., Loos, J., Lyulin, O.M., Massie, S.T., Mikhailenko, S.N., MoazzenAhmadi, N., Müller, H.S.P., Naumenko, O.V., Nikitin, A.V., Polyansky, O.L., Rey, M., Rotger, M., Sharpe, S.W., Sung, K., Starikova, E., Tashkun, S.A., VanderAuwera, J., Wagner, G., Wilzewski, J., Wcisło, P., Yu S., Zak E.J., "The HITRAN2016 molecular spectroscopic database," J. Quant. Spectrosc. Radiat. Transfer, 203, 369 (2017)

[16] Jacquinet-Husson, N., Crepeau, L., Armante, R., Boutammine, C., Chédin, A., Scott, N.A., Crevoisier, C., Capelle, V., Boone, C., Poulet-Crovisier, N., Barbe, A., Campargue, A., Chris Benner, D., Benilan, Y., Bézard B., Boudon V., Brown L.R., Coudert L.H., Coustenis A., Dana V., Devi V.M., Fally S., Fayt A., Flaud J.M., Goldman, A., Herman, M., Harris, G.J., Jacquemart, D., Jolly, A., Kleiner, I., Kleinböhl, A., Kwabia-Tchana, F., Lavrentieva N., Lacome N., Xu L.H., Lyulin O.M., Mandin J.Y., Maki A., Mikhailenko S., Miller C.E., Mishina, T., Moazzen-Ahmadi, N., Müller, H.S.P., Nikitin, A., Orphal, J., Perevalov, V., Perrin, A., Petkie, D.T., Predoi-Cross, A., Rinsland, C.P., Remedios, J.J., Rotger, M., Smith, M.A.H., Sung, K., Tashkun, S., Tennyson, J., Toth, R. A., Vandaele, A. C., Vander Auwera, J., "The 2009 edition of the GEISA spectroscopic database," J. Quant. Spectrosc. Radiat. Transf., 112, 2395-2445 (2011)

[17] Jacquinet-Husson, N., Armante, R., Scott, N.A., Chédin, A., Crépeau, L., Boutammine, C., Bouhdaoui, A., Crevoisier, C., Capelle, V., Boonne, C., Poulet-Crovisier, N., Barbe, A., Chris Benner, D., Boudon, V., Brown, L.R., Buldyreva, J., Campargue, A., Coudert, L.H., Devi, V.M., Down, M.J., Drouin, B.J., Fayt, A., Fittschen, C., Flaud J.-M., Gamache R.R., Harrison J.J., Hill C., Hodnebrog Ø., Hu S.-M., Jacquemart D., Jolly A., Jiménez, E., Lavrentieva, N.N., Liu, A.-W., Lodi, L., Lyulin, O.M., Massie, S.T., Mikhailenko, S., Müller, H.S.P., Naumenko O.V., Nikitin A., Nielsen C.J., Orphal J., Perevalov V.I., Perrin A., Polovtseva E., PredoiCross, A., Rotger, M., Ruth, A.A., Yu, S.S., Sung, K., Tashkun, S.A., Tennyson, J., Tyuterev, Vl.G., Vander Auwera, J., Voronin, B.A., Makie, A. "2015 edition of the GEISA spectroscopic database," J. of Molecular Spectroscopy, 327, 31-72 (2016). 
[18] Mlawer, E. J., Payne, V.H., Moncet, J.-L., Delamere, J.S., Alvarado, M.J. and Tobin, D. C. "Development and recent evaluation of the MT_CKD model of continuum absorption," Phil. Trans. R. Soc. A., 370, 2520-2556 (2012)

[19] Anderson, G.P., Clough, S.A., Kneizys, F.X., Chetwynd, J.H., and Shettle, E.P., [AFGL Atmospheric Constituent Profiles (0-120 km), AFGL-TR-86-0110, AFGL (OPI)], Hanscom AFB, MA 01736

[20] Ptashnik, I.V., Shine, K.P., "Calculation of solar radiative fluxes in the atmosphere: the effect of updates in spectroscopic data," Atmospheric and oceanic optics, 16(3) 251-255 (2003) 